\title{
Plantas hospederas de los virus más importantes que infectan el melón, Cucumis melo (Cucurbitaceae) en Costa Rica
}

\author{
M.V. Sánchez', R. Agüero² y C. Rivera' \\ Centro de Investigación en Biología Celular y Molecular (CIBCM), Universidad de Costa Rica, 2050, Costa Rica, fax (506) \\ 224 6749, crivera@cariari.ucr.ac.cr \\ : Centro de Investigación en Protección de Cultivos (CIPROC), Universidaad de Costa Rica, 2050, Costa Rica, \\ raguero@cariari.ucr.ac.cr
}

Recibido 03-X-1996. Corregido 14-VIII-1997. Aceptado 09-1-1998.

\begin{abstract}
Natural hosts of four melon viruses (cucumber mosaic virus o CMV, papaya ringspot virus o PRSV, watermelon virus 20 WMV-2 and zucchini yellow mosaic virus o ZYMV) were identified in two commercial melon farms in Costa Rica. The farms differed in management practices. Farm A had a long history of melon production in rotation with corn, sorghum and rice. Weed control was poor. Farm B was previously used as pastureland, had a shorter history of melon production, and was frequently plowed for weed control. Plant species diversity was monitored in $100 \mathrm{~m}^{2}$ quadrants on each farm over a one year period. In addition to the cultivated areas, four distinct plant communities (improved pasture field, drainage ditches, secondary forest and fallow field) in farm A, and three (spontaneus mixed species pasture field, fallow field and secondary forest) in farm B were included in the study. The number of quadrants sampled was dependent on the total cultivated area on each farm. Five sampling dates were selected during rainy and dry seasons and transition periods between seasons. Plants of each species represented in the quadrants were collected at each sampling date and identified using reference collections. Four plants of each species showing virus-like symptoms in the field were tested for the presence of the four viruses by ELISA. The total number of plant species, and the percent ground cover of each species infected at least with one of the viruses were recorded on each of the five sampling dates. A total of 86 and 72 plant species were identified in sites A and B, respectively. Fourteen plant species, $16 \%$ of the total plant species represented in site A, and six species in site B $(8 \%)$ were found to be infected with at least one of the four melon viruses at different times throughout the year. All four viruses were detected in each location at each of the five sampling dates, indicating that weed species naturally occurring in and around areas of commercial melon production serve as reservoirs for the melon viruses and ensure the survival of the viruses from one production season to the next. Several new host species of three of the melon viruses (PRSV, WMV-2 and ZYMV) were identified. Previously unreported hosts of PRSV included Tridax procumbens, Cleome viscosa, Cleome spinosa, Malvaviscus arboreus and Sida rhombifolia. New hosts of WMV-2 included C. viscosa, Crotum argenteus. Musa pardisiaca and Ponsetia heterophylla. New hosts of ZYMV included Guazuma ulmifolia, Rauvolfia tetraphylla, Malachra alceifolia, Boerhavia diffusa, P, heterophylla and C. viscosa.
\end{abstract}

Key words. Papaya ringspot virus, watermelon mosaic virus-2, cucumber mosaic virus, zucchini yellow mosaic virus, wild host plants, plant communities, plant species diversity.

El cultivo del melón (Cucumis melo L) es un importante producto agrícola de exportación en Costa Rica (Anónimo 1992). Se siembra principalmente en las provincias de Guanacaste y Puntarenas durante la estación seca (diciembre a abril) bajo irrigación. En estudios realizados durante los años 1989 a 1992 se identificaron cuatro virus infectando el melón en Costa Rica: el virus de la mancha anular de la papaya o "papaya ringspot virus"(PRSV), el virus del mosaicode la sandía 2 o "watermelon mosaic virus 2 (WMV2), el virus del mosaico del pepino o "cucumber 
mosaic virus" (CMV), y el virus del mosaico amarillo del zapallo italiano o "zucchini yellow mosaic virus" (ZYMV) (Rivera etal. 1991, 1993). Estudios realizados en otros paises informan que estos cuatro virus identificados en Costa Rica causan efectos severos sobre la producción y calidad de los frutos y son transmitidos en forma no persistente por varias especies de áfidos (Homoptera: Aphididae) (Lisa y Lecoq 1984, Purcifull et al.1984, Hamilton 1985, Blua \& Perring 1989, Castle et al. 1992 y Wang et al. 1992). También se conoce que para que ocurra la diseminación de virus transmitidos en forma no persistente es necesaria la presencia de fuentes de inóculo primario(Mattews 1991). Thresh (1981) reconoce a las malezas y plantas voluntarias hospederas de virus que crecen dentro del área del cultivo y en sus alrededores como fuentes importantes a partir de las cuales puede ocurrir la introducción de un virus no persistente a un cultivo.

Actualmente se carece de información acerca de los posibles reservorios naturales de estos virus en nuestro país. Debido a su importancia, el presente estudio se orientó a desarrollar un método que permitiera el estudio y análisis de hospederas naturales de los virus, en diferentes comunidades vegetales aledañas y asociadas a los campos cultivados de melón, durante cualquier época del año.

\section{MATERIALES Y MÉTODOS}

Características de las fincas: El presente estudio se realizó en dos fïncas ( $\mathrm{A}$ y B) donde se cultiva melón para la exportación. La finca A, ubicada en Filadelfia, en la provincia de Guanacaste, tiene una extensión de 480 ha y le corresponde una zona de vida "Bosque Seco Tropical de Bajura y Transición a Húmedo" (Holdridge 1978). La finca B, se ubica en Caldera, provincia de Puntarenas con una extensión de 48 ha y le corresponde una zona de vida vegetal "Bosque Tropical Húmedo de Bajura y Transición a Premontano" (Holdridge 1978).

\section{Selección de los cuadrantes para muestreo:} En cada finca, se identificaron, seleccionaron y ubicaron las diferentes comunidades vegetales existentes que formaban parte del área de cultivo y sus linderos (Cuadro 1). Cada comunidad seleccionada se dividió en cuatro partes iguales, escogiéndose en forma aleatoria una de ellas como cuadrante de muestreo. Para comprobar si los cuadrantes seleccionados en cada finca representabanlasespecies silvestresque formaban la comunidad vegetal respectiva, se hizo un levantamiento de especies en un transecto en forma de equis $(\mathrm{X})$, de aproximadamente $1 \mathrm{~m}$ de ancho a lo largo de cada comunidad vegetal. El tamaño del cuadrante para muestreo se determinó por el criterio de área mínima, la que se define como el área en la cual están presentes la totalidad de las especies que representan esa comunidad y en donde al aumentar el área no aumenta el número de especies diferentes.

\section{CUADRO}

Cuadrantes seleccionados y área total muestreada en cada comunidad vegetal.

Selected quadrants and total area sampled in each type of plant community.

Comunidad vegetal No. de cuadrantes Área total $\left(\mathrm{m}^{2}\right)$

Finca A

$\begin{array}{lcc}\text { Área de cultivo } & 10 & 1000 \\ \text { Charral o tacotal } & 4 & 1720 \\ \text { Canal de drenaje } & 2 & 315 \\ \text { Semi-bosque } & 2 & 600 \\ \text { Potrero mejorado } & 2 & 1725\end{array}$

Finca B

$\begin{array}{lcc}\text { Área de cultivo } & 5 & 500 \\ \text { Charral o tacotal } & 3 & 340 \\ \text { Pastizal natural } & 1 & 100 \\ \text { Semi-bosque } & 1 & 300\end{array}$


El número de cuadrantes de muestreo en la totalidad de comunidades vegetales se determinó con base en el área de cada comunidad (menor de 15 ha, tres cuadrantes; entre 15 y 60 ha, cinco cuadrantes; y mayor de 60 ha, diez cuadrantes) según lo proponen Soto y Agüero (1992) (Cuadro $1)$.

Identificación taxonómica de plantas silvestres: En cada cuadrante seleccionado, se realizó un inventario total delas plantas silvestres (arbustos y herbáceas, excluyendo ciperáceas y gramíneas)en cincoépocas diferentes distribuidas en un año calendario (en la época seca en los meses de febrero y abril, cuando hay melón sembrado en el campo, al inicio de la época lluviosa en junio y durante la época lluviosa en setiembre, cuando no hay cultivo en el campo; $y$ a finales de la época lluviosa, en noviembre, poco antes de iniciarse la siembra de melón). Las plantas fueron identificadas utilizando las colecciones de referencia existentes en el Herbario Nacional de Costa Rica (Museo Nacional) y en el Instituto Nacional de Biodiversidad (INBio).

Identificación de especies hospederas de virus: Del inventario total de plantas realizado en cada una de las fincas, se recolectaron muestras de todas aquellas especies que presentaban síntomas similares a los inducidos por virus y se guardarona $-20^{\circ} \mathrm{C}$. LatécnicadeELISA(enzymelinked immunosorbentassay)dedoble "sandwich" de anticuerpo (ELISA-DAS) se utilizó para identificar los virus PRSV, WMV-2 y CMV y el método de ELISA indirecto para ZYMV. Para CMV se utilizó anticuerpos policlonales y anticuerpos conjugados a fosfatasa alcalina. Para PRSV, WMV-2yZYMV se utilizaron anticuerpos policlonales y anticuerpos conjugados a peroxidasa. Del total de plantas recolectadas por especie, se seleccionaron para los análisis, mediante un muestreo aleatorio simple de tipo probabilístico sin reemplazo (Wayne 1988), las siguientes categorías: especies previamente reportadas en la literatura como hospederas de alguno de los virus en estudio, y aquelllas no reportadas previamente en la literatura. Aproximadamente cuatro muestras de las plantas recolectadas por especie fueron analizadas. Se tomaron como ELISA positivas todas aquellas muestras que presentaron valores de absorbancia a $405 \mathrm{~nm}$ para fosfatasa alcalina y $490 \mathrm{~nm}$ para peroxidasa, mayoreso iguales a la media $(X)$, más tres desviaciones estándar (3s) de los valores de las muestras sanas control $(X+3 s)$, donde $n=6$.

Determinación del porcentaje de cobertura vegetal y abundancia a través del tiempo: $L a s$ especies identificadas como hospederas de virus, fueron clasificadas de acuerdo a su porcentaje de cobertura (proporción de terreno ocupado por la proyección perpendicular de las partes aéreas de los individuos de la especie considerada (Matteucci y Colma 1982) y por su abundancia durante las cinco épocas estudiadas, según la metodología descrita por Soto y Agüero (1992). Los datos obtenidos fueron distribuidos en Figs. que combinan la especie de interés, su cobertura vegetal y laépoca de su aparición en las diferentes comunidades vegetales.

\section{RESULTADOS}

Identificación taxonómica de especies: Se identificaron un total de 86 especies silvestres distribuidas en 49 familias de plantas en la finca A y 72 especies distribuidas en 40 familias en la finca $\mathrm{B}$, de las cuales 23 y 12 especies respectivamente mostraron síntomas virales en el campo (Cuadro 2). 
CUADRO 2

Total de especies silvestres identificadas taxonómicamente en ambas fincas Total inventory of weeds in both farms.

Familia

Finca
Finca

A $\quad$ B

Bignoniaceae

$\begin{array}{lll}\text { Crescentia cujete } & \mathrm{x} & \mathrm{x} \\ \text { spp. } & \mathrm{x} & \mathrm{x} \\ \text { spp. } & \mathrm{x} & \mathrm{x} \\ \text { Tabebuia rosea } & \mathrm{x} & \mathrm{x} \\ \text { spp. } & & \mathrm{x}\end{array}$

Boraginaceae

Tournefortia hirsutissima $\quad \mathrm{x}$

Heliotropium indicum* ${ }^{*} \quad \mathrm{x}$

Caesalpinaceae

Bauhinia sp.

Cassia maxonii

Cassia biflora

Cassia pallida

Caesalpinia sp.

Cassia reticulata*

Capparidaceae

Cleome viscosa*

Cleome spinosa*

$B$

Anacardiaceae

Astronium graveolens

Caricaceae

Cecropiaceae

Cecropia insignis*

\section{Combretaceae}

Combretun sp.

Commelinaceae

Commelina difussa

$\mathrm{x}$

Convulvulaceae

Aniseria martinicensis Ipomoea nil 
Familia

Finca

A $B$

Ipomoea sp.

$\mathrm{X}$

Cucurbitacea

Momordica charantia*

Cucumis melo*

Dioscoreaceae

Dioscorea sp.

Euphorbiaceae

Manihot esculenta
Croton argenteus*
Poinsetia heterophylla*
Caperonia palustris*
Chamaesyce hyssopifolia
Phyllantus amarus
Ricinus comunis

Flacourtiaceae

Calearia corymbosa

Lamiacea

Hiptis suaveolens

Loasaceae

Gronovia scandens*

Malvaceae

Malachra sp.

Malvaviscus arboreus

Sida rhombifolia*

Malachra alceifolia*

Sida decumbens

Marantacea

Calathea sp.

Mimosaceae

Mimosa pigra

Mimosa pudica

Pithecellobium.oblongum

Acacia costarricensis

Albizia caribaea
Familia

Finca

A

Moraceae

Chlorophora tinctoria

Musaceae

Musa paradisiaca*

Myrtaceae

Eugenia valerii

Nyctaginaceae

Pisonia macrocarpa $\quad \mathrm{x}$

Boerhaavia diffusa*

Onagraceae

Ludwigia erecta

$\mathrm{x}$

Papilionaceae

Crotalaria retusa

Desmodium sp.

Centrosema pubescens

ssp.

Passifloraceae

Passiflora foetida*

Passiflora sp.

Passiflora biflora

Passiflora edulis

Phytolaccaceae

Petiveria alliaceae*

Piperaceae

Piper sp.

Polygonaceae

Coccoloba caracasana

Triplaris americana

Triplaris melaenodendron

$x \quad x$

$x \quad x$

Portulaccaceae

Portulaca oleracea 
Familia

Finca

A

B

Rubiaceae

\section{Palicourea sp.}

Psychotria sp.

Chomelia spinosa

Sapindaceae

Serjanias sp.

Scrophulariaceae

Stemodia durantifolia

Simaroubaceae

Simarouba glauca

$\mathrm{X}$

Smilacaceae

Smilax sp.

Solanaceae
Physalis ignota*

Physalis angulata*

Lycianthes lenta

Solcinum sp.

Physalis sp.
Familia

Finca
B

Sterculiaceae

Walteria americana

Melochia sp.

Sterculia apetala

Melochia villosa*

Guazuma ulmifolia*

Tiliaceae

Corchorus orinocensis

Verbenaceae

Lantana camara*

Vitaceae

Cisus sycyoides

Cisus sp.

$\mathrm{x}$

* Especies que presentaron síntomas virales en el campo.
Identificación de especies hospederas de virus: De las 23 especies en la finca A y de las 12 especies en la finca B que presentaron síntomas virales, 14 y seis especies respectivamente fueron positivas por lo menos para uno de los cuatro virus analizados; el resto de las especies sintomáticas analizadas fueron negativas paralos virus estudiados (Cuadro 3). Algunas especies en ambas fincas fueron encontradascomohospederas de un solo virus (CMV o PRSV), otras especies lo fueron de dos, tres y hasta los cuatro virus. Varias especies de plantas hospederas no informadas anteriormente fueron identificadas para tres de los virus del melón (PRSV, WMV-2 y ZYMV) (Cuadro 3). 


\section{CUADRO 3}

Resultados del análisis por ELISA de las especies sintomáticas recolectadas en ambas fincas. ELISA results of symptomatic plants species collected in both farms.

Familia

$$
\text { PRSV }
$$$$
\text { WMV-2 CMV }
$$$$
\text { ZYMV }
$$$$
\text { PRSV }
$$

WMV-2 CMV

ZYMV

Finca A

Finca B

Acanthaceae

\section{Justicia comata}

Amaranthaceae

Amaranthus spinosus Alternanthera sp.

\section{Apocynaceae}

Rauvol fia tetraphylla

Asteraceae

Tridax procumbens

Boraginaceae

Heliotropium indicum

Caesalpinaceae

Cassia reticulata

\section{Capparidaceae}

Cleome viscosa

Cleome spinosa

\section{Caricaceae}

Carica papaya

Cecropiaceae

Cecropia insignis

\section{Cucurbitaceae}

Momordica charantia Cucumis melo*

\section{Euphorbiaceae}

Croton argenteus

Poinsetia heterophylla Caperonia palustris 
Familia

Loasaceae

Gronovia scandens

\section{Malvaceae}

Malvaviscus arboreus

Sida rhombifolia

Malachra alceifolia

Musaceae

Musa paradisiaca

Nyctaginaceae

Boerhaavia diffusa

Passifloraceae

Passiftora foetida

Phytolaccaceae

Petiveria alliaceae

Solanaceae

Physalis ignota

Physalis angulata

Sterculiaceae

Guazuma ulmifolia Melochia villosa

Verbenaceae

Lantana camara

+ Positiva, - Negativa; * Melón voluntario (fl de la variedad de melón sembrada inicialmente, cuya semilla queda como parte del rastrojo en el campo).

** No informada previamente por la literatura como hospedera de alguno de los 4 virus.

\section{Determinación del porcentaje de cobertura} vegetal y abundancia a través del tiempo: Se observaron diferencias en la diversidad, en el porcentaje de cobertura vegetal, abundancia y epoca de aparición en el campo de las especies hospederas en las diferentes comunidades vegetales (Fig. 1). 

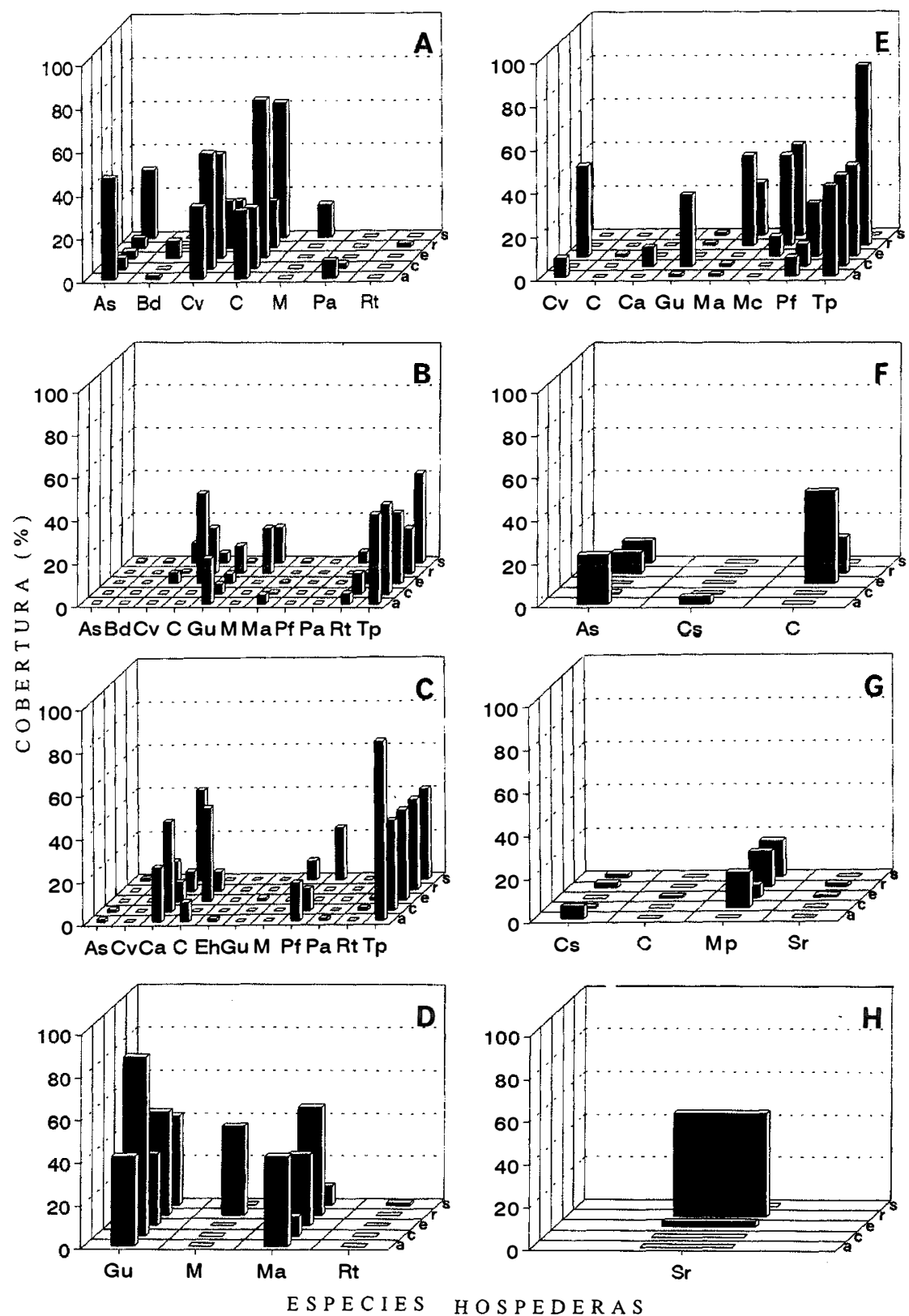

Fig. 1. Porcentaje de cobertura vegetal y distribución en el tiempo de las especies hospederas de virus identificadas en las diferentes comunidades vegetales. Finca A: A) área de cultivo, B) charral, C) canal de riego, D) semi-bosque, E) potrero mejorado. Finca B: F) área de cultivo, G) charral, H) pastizal natural. Amaranthusspinosus (As), Boerhaavia diffusa (Bd), Cleome spinosa (Cs), Cleome viscosa (Cv), Croton argenteus (Ca), Cucumis melo (C), Euphorbia heterophylla (Eh), Guazuma ulmifolia (Gu), Malachra alceifolia (M), Malvaviscus arboreus (Ma), Momordica charantia (Mc), Musa paradisiaca (Mp), Passiflora foetida (Pf), Physalis $\operatorname{angulata}(\mathrm{Pa})$, Rauvolfia tetraphylla $(\mathrm{Rt})$, Sida rhombifolia $(\mathrm{Sr})$, Tridax procumbens $(\mathrm{Tp})$. Febrero (a), abril (c), junio (e), setiembre (r) y noviembre(s). 


\section{DISCUSIÓN}

La metodología utilizada en este trabajo permitió en dos zonasecológicas diferentes donde se cultiva melón: 1- identificar la diversidad de plantas silvestres en diferentes comunidades vegetales (Cuadro 2), 2- determinar entre ellas, aquellas plantas hospederassilvestres de los virus estudiados (Cuadro 3), 3-determinar la cobertura, abundancia, persistencia y distribución en el tiempo de aquellas especies hospederas de virus en las diferentes comunidades vegetales (Fig. 1) y, 4- identificar nuevas especies silvestres como hospederas de virus (Cuadro 3). Entre las principales ventajas que ofreció la metodología diseñada está su aplicabilidad en diferentes comunidades vegetales naturales en diferentes épocas del año.

Debido a la diversidad de especies existentes en los trópicos, para seleccionar los cuadrantes de muestreo fuera del área de cultivo, fue necesario adaptar el método propuesto por Soto y Agüero (1992). En éste se consideran la extensión de la finca y la heterogeneidad de especies existentes en las diferentes asociaciones o comunidades vegetales, y además se comprueba que la vegetación encontrada en cada cuadrante sea representativade la comunidad vegetal respectiva. Los cuadrantes se seleccionaron únicamente en el mes de febrero (primer muestreo), debido al extensotrabajoque esto requiere, y semantuvieron sin modificar durante los muestreos posteriores. Estopermitiódeterminar loscambiosde cobertura, variabilidad de las especies a traves del tiempo y en las diferentes comunidades vegetales, en relación con los principales cambios climáticos y con la presencia o no del cultivo. Otros métodos previamente utilizados en estudios vegetacionales determinan los cuadrantes de muestreo como el área donde existe una población vegetal homogénea y los denominan área mínima de muestreo (Mueller-Dombois y Ellemberg 1974, Matteucci y Colma 1982). Estecriterioes aplicable principalmente en las regiones templadas, donde por sus características climáticas el crecimiento, abundancia y diversidad de especies vegetales es escazo, por lo tanto en nuestro caso se aplicó únicamente dentro del área de cultivo, área que por sísola representa una comunidad vegetal muy homogénea y en la que además, se controla normalmente la colonización de plantas silvestres.

La mayoría de las especies silvestres y especies cultivables informadas previamente en otros trabajos como hospederas de alguno de los virus PRSV, WMV-2, CMV y ZYMV, han sido identificadas experimentalmente en invernadero mediante pruebas de inoculación mecánica, y pruebas de transmisión con áfidos vectores hacia plantas indicadoras. La presencia de virus ha sido detectada principalmente mediante la sintomatología que éstos inducen en las plantas (Merrit y Tuttle 1969, Makkouk y Lessemann 1980, Lisa et al. 1981, Adlerz et al. 1983, Xu y Barnett 1984, Davis y Mizuki 1987, Wang et al. 1992). En esta investigación, a diferencia de las anteriores, se utilizó el método de ELISA para detectar los virus directamente de las plantas silvestres recolectadas en el campo, pues el usode una metodología sensible y específica como ELISA, facilita el análisis e identificación de los virus en un gran número de muestras, y provee resultados más precisos y confiables que los obtenidos mediante el uso de sintomatología y ámbito de hospederas (Davis y Mizuki 1987). Como se puede observar no todas las especies recolectadas con síntomas en este trabajo fueron positivas por ELISA para alguno de los virus analizados (Cuadro 3). Estas especies negativas podrían ser hospederas naturales de otros virus no estudiados en este trabajo, o los síntomas no estar asociados a ninguna infección viral, o que la concentración de virus en la planta sea menor a los límites de detección del método de ELISA utilizado. Por otro lado, pocos estudios previos similares al presente, se han realizado para determinarlashospederas silvestres deestoscuatro virus en los trópicos, como resultado de la transmisiónnatural de ellos en el campo (Valdivia 1991, Ullman et al. 1991). A diferencia de ellos, nuestra investigación se realizó en cinco distintas épocas del año, y las especies hospederas se ubicaron en comunidades vegetales representativas y previamente seleccionadas. 
Un mayor número de especies silvestres se identificaron en la finca A (86 especies) con respecto a la finca B (72 especies). Esto podría explicarse con base en las diferenciasen extensión entre ambas fincas. También la diversidad de hospederas de virus en la finca $\mathrm{A}$, fue mayor que en la B (Cuadro 2). En la finca A, predominó un mayor número de especies silvestres hospederas de ZYMV, seguido de WMV-2, CMV y PRSV. En la finca B, predominó igual número de especies silvestres hospederas paraPRSV y CMV, seguidas de ZYMV y WMV-2. Esta mayor diversidad de hospederas de virus en la finca $\mathrm{A}$, parece tener relación con la diversidad vegetal general encontrada en ella. La diferencia en diversidad de hospederas puede deberse a factores climáticos y bióticos, así como a los diferentes usos que se le ha dado a la tierra en años anteriores y a diferencias en el manejo cultural, los cuales pudieron haber contribuido en el tiempo a la diferencia en diversidad (Jurgens 1985). Por ejemplo, la finca A tiene varios años dedicada al cultivo del melón para la exportación y la rotación de este cultivo con maíz, sorgo y arroz durante el resto del año. La finca $B$ por el contrario, tiene menos tiempode cultivar melón y antes de esta actividad el área de cultivo estaba destinada a la ganadería. Además, durante las épocas en que se realizó esta investigación, la finca B se caracterizó por controlar las malezas, arando el área de cultivo con mayor frecuencia, para mantener baja su población.

Al comparar la distribución y persistencia de la mayoría de las especies hospederas de virus en las diferentes comunidades vegetales, se observó que algunas especies persisten durante todo el año con una gran abundancia relativa y cobertura, mientras otras lo hacen durante períodos más cortos y presentan una abundancia y cobertura muy variable (Fig. 1). Sin embargo, la diversidad, abundancia, cobertura y permanencia de algunas especies parecen garantizar la subsistencia de los cuatrovirus estudiados, aunque noexista el cultivo del melón en el campo. Rivera et al. (1993), reportan la presencia de PRSV, WMV-2, ZYMV y CMV en cultivares de melón para la exportación en Costa Rica, durante los períodos 1989-1990 y
1990-1991. La presencia de estos virus y la diversidad de hospederas determinadas en las zonas de estudio, son un riesgo potencial para el cultivo del melón en Costa Rica, ya que han sido reportados efectos severos en la producción de cucurbitáceas causados por estos virus en otras regiones del mundo(Makkouk y Lesemann 1980, Purcifull et al. 1984, Blua y Perring 1989).

En ambas fincas, se identificaron algunas especies hospederas de un solo virus (CMV o PRSV) y especies hospederas de dos, tres y hasta los cuatro virus estudiados, infectandoen algunos casos diferentes mezclas de ellos una misma planta. Infecciones simples y mixtas de estos cuatro virus fueron observadas con frecuencia en el campo en el cultivo de melón (Rivera et al. 1993).

En ambas fincas también se identificaron plantas hospederas silvestres que no han sido previamente informadas por la literatura. Entre las especies nuevas detectadas, aparecieron para PRSV cincoespecies representadas en tres familias no reportadas (Asteraceae, Capparidaceae y Malvaceae); para WMV-2 cinco especies y para ZYMV siete especies (Cuadro3). La aparición de especies hospederas previamente no reportadas, no debe sorprender debido a los pocos estudios realizados con este propósito, en una región tan rica en diversidad vegetal como lo es el trópico.

El conocer los reservorios naturales de los virus que infectan el melón de exportación en Costa Rica en condiciones de clima tropical, permitirádesarrollar y probar diferentes medidas de control preventivo para estas virosis. La erradicación de hospederas de virus en el área de cultivo y su vecindad, durante todoel año, podrían reducir las fuentes naturales de inóculo iniciales. En general,parael controlde enfermedades virales no es suficiente la aplicación de una sola medida de control, sino más bien, la utilización de una serie de medidas de control integrado, para minimizar los daños que puedan producir en el cultivo. El llevar a cabo un manejo adecuado de plantas silvestres en el trópico, es muy difícil por la diversidad de especies que existe; sin embargo 
una posible alternativa para eliminar comunidades vegetales aledañas al cultivo, y que sirvan como reservorios de virus, es la de crear alrededor potreros mejorados donde se pueda tener un buen control de las malezas y de esta manera tratar de reducir los efectos producidos por estas virosis en el cultivo del melón.

\section{AGRADECIMIENTOS}

Esta investigación fue financiada por CINDE (Coalición Costarricense de Iniciativas para el Desarrollo) y laCámara Nacional de Exportadores y Productores de Melón de Costa Rica. Fue realizada como parte del Programa de Caracterización y Diagnóstico de Virus y Viroides en Cultivos de Importancia Económica del Centro de Investigaciones en Biología Celular y Molecularde la Universidad de CostaRica(PCDV - CIBCM - UCR). Los autores agradecen a Lisela Moreira, Melanie Hord y Ana Victoria MacayaLizano la revisión del manuscrito.

\section{RESUMEN}

Las especies hospederas naturales de los virus (PRSV, WMV-2, CMV y ZYMV) que infectan el cultivo de melón (Cucumis melo L.) para la exportación en Costa Rica se identificaron en plantaciones comerciales de dos fincas ubicadas, una en la provincia de Guanacaste, y la otra en la provincia de Puntarenas. En ambas fincas se cultiva el melon con irrigación durante la época seca, pero su manejo cultural es diferente. La finca A con una larga trayectoria en el cultivo de melón en rotación con maíz, sorgo y arroz, y con poco control de malezas; mientras que la finca B con una corta trayectoria en la producción del melón y un mayor control de malezas. La diversidad de especies vegetales fue estudiada en cuadrantes de $100 \mathrm{~m}^{2}$ en cinco diferentes comunidades de plantas previamente seleccionadas en la finca A (cultivo, canal de drenaje, charral, potrero mejorado, y semi-bosque) y tres en la finca B (cultivo, charral, pastizal natural, semibosque). El número de cuadrantes estudiados dependió del área total cultivada en cada una de las fincas. Todas las especies de plantas representadas en cada cuadrante se recolectaron e identificaron pero solo aquellas especies que presentaron síntomas virales en el campo fueron analizadas por ELISA para determinar la presencia de los cuatro virus estudiados. La diversidad de especies, porcentaje de cobertura y épocade aparición de las especies hospederas fuemonitoreada durante un año calendario en cinco fechas diferentes. Un total de 86 y 72 especies de plantas fueron identificadas en las fincas A y B respectivamente. Catorce encontradas positivas por lo menos para uno de los cuatro virus. Los cuatro virus fueron encontrados en cada finca en cada fecha de muestreo indicando que la permanencia y abundancia dealgunasespecies hospederas garantiza la permanencia de los cuatro virus en el campo como fuente de inóculo primario para la próxima siembra. Varias especies de plantas hospederas silvestres previamente no informadas en la literatura fueron encontradas para PRSV, WMV-2 y ZYMV.

\section{REFERENCIAS}

Adlerz W.C., D.E. Purcifull, G.W. Simone \& E. Hiebert. 1983. Zucchini yellow mosaic virus: a pathogen of squash and other cucurbits in Florida. Proc. Fla. St. Hort. Soc. 96: $72-74$.

Anónimo. 1992. Perfil del cultivo de melón. CINDE, San José, Costa Rica. 16 p.

Blua M.J. \& T.M. Perring. 1989. Effect of zucchini yellow mosaic virus on development and yield of cantaloupe (Cucumis melo). Plant Dis. 73: 317-320.

Castle S.J., T.M. Perring, C.A. Farrar \& A.N. Kishaba. 1992. Field and laboratory transmission of watermelon mosaic virus 2 and zucchini yellow mosaic virus by various aphid species. Phytopathology 82: 235-240.

Davis R.F. \& M.K. Mizuki. 1987. Detection of cucurbit viruses in New Jersey. Plant Dis. 71: 40-44.

Hamilton R.I.. 1985. Virus transmission, p. 245-267. In Francki R.I.B. (ed.). The Plant Viruses: polyhedral virions with tripartite genomes. Plenum, Nueva York.

Holdridge L.P. 1978. Ecología basada en las zonas de vida. IICA, San José, Costa Rica. 77 p.

Jurgens G. 1985. Levantamiento de malezas en cultivos agrícolas. In Resúmenes del Seminario Manejo Integrado de Malezas. PLITS. 3(2): 85-104.

Lisa V., G. Boccardo, G. D“Agostino, G. Dellavalle \& M.D. 'Aquilio. 1981. Characterization of a potyvirus that causes zucchini yellow mosaic. Phytopathology 71: 667-672.

Lisa V. \& H. Lecoq. 1984. Zucchini yellow mosaic virus. No. 282. In: Descriptions of plants viruses. Commonw. Mycol. Inst./Assoc. Appl. Biol., Kew, Inglaterra. 4 p. 
Makkouk K.M. \& D.E. Lesemann. 1980. A severe mosaic of cucumbers in Lebanon caused by watermelon mosaic virus-1. Plant Dis. 64: 799-801

Matteucci S.D. \& A. Colma. 1982. Metodología para el estudio de la vegetación. Secretaría General de la Organización de los Estados Americanos. Programa Regional de Desarrollo Científico y Tecnológico. Washington, D.C.. 163 p.

Matthews R.E.F. 1991.Plant Virology. Academic, San Diego, California. $835 \mathrm{p}$.

Merritt R.N. \& D.M. Tuttle. 1969. The epidemiology of cucumbermosaic and watermelon mosaic 2 of cantaloupes in an arid climate. Phytopathology 59: 849-856.

Mueller-Dombois D. \& H.Ellenberg. 1974. Aimsand methods of vegetation ecology. Willey, Nueva York. 547 p.

Purcifull D.E., Edwardson J., Hiebert E. \& D. Gonsalves. 1984. Papaya ringspot virus. No 292. In: Descriptions of plant viruses. Commonw. Mycol. Inst./Assoc. Appl. Biol., Kew, Inglaterra. $4 \mathrm{p}$.

Rivera C., P. Ramírez \& C.M. Rodríguez. 1991. Papaya ringspot virus and cucumber mosaic virus associated to a severe mosaic in melon in Costa Rica. Turrialba 41: 437443.

Rivera C., W. Villalobos, M.V. Sánchez, C. Zumbado \& C.M. Rodríguez. 1993. Identification and distribution of viruses infecting melon and their vectors in Costa Rica. Turrialba 43: $210-215$
Soto A. \& R. Agüero. 1992. Combate químico de malezas en el cultivo del arroz. Universidad de Costa Rica, San José, Costa Rica. 81 p.

Thresh J.M. 1981. The role of weeds and weed plants in the epidemiology of plant virus diseases, p. 53-70. In: J.M. Thresh (ed.). Pests, pathogens and vegetation. Pitman, Londres.

Ullman D.E., J.J. Cho \& T.L. German. 1991. Occurrence and distribution of cucurbit viruses in the Hawaiian Islands. Plant Dis. 75: 367-370.

Valvidia-Torres A.R. 1991. Determinación de los virus de melón y sus malezas hospederas en Choluteca, Honduras. M.Sc.Tesis, CATIE, Turrialba, Costa Rica. 76 p.

Wang H.L., D. Gonsalves, R. Providenti \& T.A. Zitter. 1992. Comparative biological and serological properties of four strains of zucchini yellow mosaic virus. Plant Dis. 76: 530-535.

Wayne W.D. 1988. Bioestadística: Base para el análisis de las ciencias de la salud. LIMUSA, México. 667 p.

Xu Z. \& O.W. Barnett. 1984. Identification of a cucumber mosaic virus strain from naturally infected peanuts in China. Plant Dis. 68: 386-389. 